\title{
Optical backscatter method for determining thermal denaturation of $\beta$-lactoglobulin and other whey proteins in milk
}

\author{
Alisa Lamb, ${ }^{* 1}$ Fred Payne, ${ }^{*}$ Youling L. Xiong, $†$ and Manuel Castillo* $¥$ \\ *Department of Biosystems and Agricultural Engineering, and \\ †Department of Animal and Food Sciences, University of Kentucky, Lexington 40546 \\ łDepartment of Animal and Food Sciences, Universitat Autònoma de Barcelona, 08193 Bellaterra, Spain
}

\begin{abstract}
The heat denaturation of whey proteins affects the functional properties of milk. Correlations of $\beta$-lactoglobulin ( $\beta-\mathrm{LG})$ denaturation to gelation time, gel firmness, and gel moisture content have been widely documented. Currently, no technique is available for quantifying $\beta$-LG denaturation in milk without altering its native composition or requiring a laborious procedure. The goal of this study was to establish if an optical backscatter response of whey protein denaturation during milk heat treatment could be determined that would be the basis for an inline optical measurement technology. The experimental design consisted of 1 factor (time at $80^{\circ} \mathrm{C}$ ) and 6 levels $(0,3,5,7,12$, and $25 \mathrm{~min}$ ). Physicochemical analysis performed indicated that $\beta$-LG denaturation followed a first-order response during thermal treatment. The light backscatter response, measured as a ratio of two 25-nm wave bands $(832.5 \mathrm{~nm} / 382.5 \mathrm{~nm})$, significantly correlated to $\beta-\mathrm{LG}$ denaturation and had a $14 \%$ increase for milk with $75 \% \beta$-LG denaturation. The strength of the optical response at the proposed wave bands and their correlation to denaturation suggests that light backscatter could potentially be used to measure $\beta-\mathrm{LG}$ and other whey protein denaturation inline.
\end{abstract}

Key words: light backscatter, optical sensor, inline, whey protein denaturation

\section{INTRODUCTION}

The dynamic $\$ 110$ billion US dairy industry (IDFA, 2010) is extraordinarily complex and plays an influential role in the American diet. According to the International Dairy Food Association, approximately 0.77 billion kilograms of cheese was produced in 2009 . Over $96 \%$ of Americans purchase cheese products, and the consumption of cheese has been rising since 2000 .

Received May 31, 2012.

Accepted December 3, 2012.

${ }^{1}$ Corresponding author: alisa.lamb@gmail.com
In addition, an increasing demand exists for US dairy exports, which had a 30\% increase from 2010 to 2011 (USDEC, 2012). With these market values, efficiencies and inefficiencies in dairy processing can have a large effect on company profit and market prices.

In current dairy processing procedures, milk is exposed to heat treatment to kill pathogens, reduce the number of nonpathogenic microorganisms that could cause milk spoilage, and inactivate many indigenous enzymes, which contributes to milk stability. Exposure to heat treatment changes microstructural, rheological, and optical properties of milk and its coagulation behavior. The abundance of cysteine and methionine amino acids in the soluble whey proteins is responsible for many of the changes that occur in milk as a result of heating. $\beta$-Lactoglobulin is the most prominent sulfhydryl-containing soluble milk protein, with a denaturation temperature of $78^{\circ} \mathrm{C}$ (Brown, 1999). The protein unfolding associated with denaturation exposes the sulfhydryl groups previously buried in the protein. These groups can associate with $\kappa$-CN residing on the surface of the casein micelle or with other denatured whey proteins. Some sulfhydryl groups exposed as a result of denaturation can also contribute to $\mathrm{SH}_{2}$ release, which creates an off-flavor in milk (Walstra et al., 2001). Important changes of relevance for industrial processing occur in milk properties upon the interaction between $\beta$-LG and the casein micelle.

A slower gelation time and decreased gel firmness in milk gels result from an increase in heat treatment (Waungana et al., 1997; Allogio et al., 2000). A clear correlation exists between the temperature and (or) time of heat exposure and $\beta-\mathrm{LG}$ denaturation and an increase in that percentage corresponds with a decrease in gel firmness and longer gelation time. Because $\beta$-LG is connected to the casein micelle, it acts as a steric obstacle by limiting the rennet's access to $\kappa-\mathrm{CN}$. As a result of this protein-protein interaction, the gelation time is delayed and the milk gel is looser. The milk gel also becomes highly networked when the proteins interact as a result of heat treatment. This intense network interconnection prevents the moisture from 
being expelled from the gel (i.e., the gel cannot shrink). The moisture content increases in the gel as a result of more profuse networking and the higher water-holding capacity of whey proteins compared with casein micelles. Undenatured whey proteins contain $0.033 \mathrm{~g}$ more bound water per gram of DM than rennet casein gels (Hardy, 1989). In addition, the high-moisture gels yield poorly ripened cheese, compromising texture, flavor, and product acceptability. Lastly, the casein micelle increases in diameter after thermal denaturation of proteins. Reports indicate that the size of the casein micelle increases throughout continued damaging heat exposure but rapidly increases with high percentages of $\beta$-LG denaturation (Anema and Li, 2003). They found the maximum increase in diameter was 30 to $35 \mathrm{~nm}$, which would represent about a 30\% increase. The light backscatter from a casein micelle, or any spherical particle, varies with wavelength and diameter (Siegel and Howell, 2002). If the casein micelle does increase in size, this will increase the light backscatter of the milk.

Wheying-off, or the undesired appearance of whey on the surface of a gel during storage, is a common defect in several brands of yogurt currently on the US market. Manufacturers try to avoid this defect by increasing the solids content of the cultured milk and by adding stabilizers. Adding solids unnecessarily increases production cost. Adding stabilizers changes the genuine organoleptic attributes of yogurt, and has a negative effect on the image of yogurt as natural and additive-free dairy product. Several studies indicate that milk gels with denatured proteins expel less whey (Guyomarc'h et al., 2003), which reduces the likelihood of this defect.

Over the last decade, a variety of optical sensor technologies were developed for food process monitoring and control applications. Specifically, light-scatter measurements have been applied for monitoring milk coagulation, predicting cutting time, and estimating curd moisture content during cheese making, determining milk and whey fat concentrations, sensory attributes of cheese, and measuring the degree of meat emulsion stability during hot dog manufacturing (Payne et al., 1993; Castillo et al., 2000, 2005; Fagan et al., 2007a,b; Alvarez et al., 2009). Light backscatter and transmission are the 2 most prominent measurement configurations used for optical sensor development in food applications. As a result of the optical properties of casein micelles, they tend to scatter the most light backward (Siegel and Howell, 2002). Therefore, light backscatter was chosen for the optical measurement configuration in this study.

The objective of this study was to find a relationship between the light backscatter response in milk and the degree of denaturation of its proteins, indicating if $\beta$-LG aggregated with $\kappa$-CN, hypothesizing that if the casein micelle does increase in size after heat exposure, this will change the light backscatter of the milk. This new method, if successfully implemented, will assist dairy plants in the efficient use of raw milk and ensure production of high-quality products. Light backscatter analysis by this method would not require any composition alteration of milk and could be measured in real time. These characteristics give it the potential to be developed into an inline measurement technology for evaluating milk's suitability in cheese or yogurt manufacture based on level of whey denaturation.

\section{MATERIALS AND METHODS}

\section{Experimental Design}

A factorial heat treatment arrangement with a completely randomized design structure was used to study the potential for using light backscatter to measure whey protein denaturation in thermally processing milk. Three replications of each treatment arrangement were performed. The test factor was heat exposure time $(0,3,5,7,12$, or $25 \mathrm{~min})$. A water bath (Ecoline water bath, Lauda RE 220; Lauda-Brinkmann LP, Delran, NJ) was used to heat treat the samples. To minimize the sample warm-up time and provide for a consistent thermal treatment, a thin stainless steel enclosure was designed to serve as a heat exchanger between the water bath and milk sample (Figure 1). The milk samples were placed in 100-mL glass test tubes and warmed over a period of $30 \mathrm{~min}$ to $25^{\circ} \mathrm{C}$ in a water bath before treatment. The milk was poured in the heat exchanger submerged in the water bath at $80^{\circ} \mathrm{C}$ to initiate thermal treatment. The heat treatment was stopped after the target time by removing the heat exchanger from the water bath and cooling in an ice water bath for 3 min. The milk samples were removed from the heat exchanger, placed in a test tube, and refrigerated at $4^{\circ} \mathrm{C}$. The milk samples were warmed to $25^{\circ} \mathrm{C}$ for optical measurement. The milk sample temperature was controlled while in the optical test cell by a water jacket connected to a water bath.

\section{Optical Methodology}

The light backscatter configuration was implemented by using an optical fiber to deliver light from a lightemitting diode (LED) to the milk and an optical fiber to receive the backscattered light and deliver it to a detector (Figure 2). The light projected into the milk sample at the termination of the optical fiber is scattered in all directions by the casein micelle. Some of the scattered light will be intercepted at the termination plane of the receiving optical fiber and transmitted to 


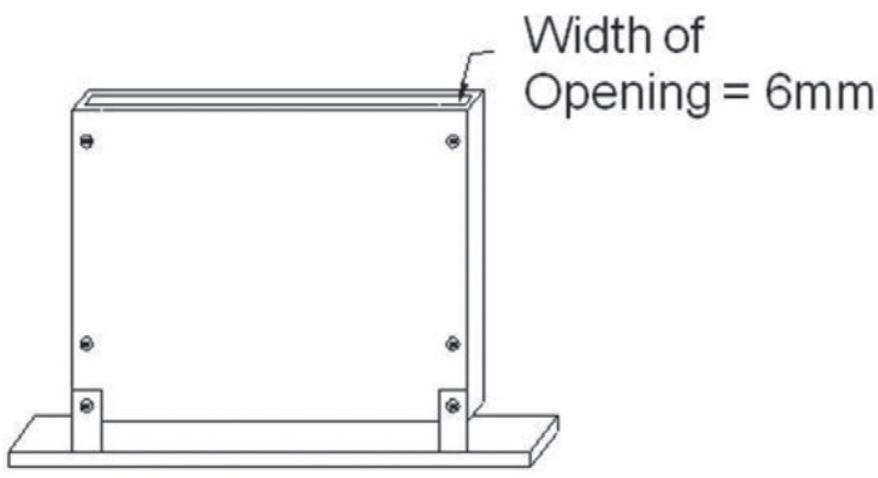

Figure 1. Parallel plate vessel used to hold the milk sample for heat treatment. The plates were spaced $6 \mathrm{~mm}$ apart to hold a maximum volume of $100 \mathrm{~mL}$.

the detector. The detector outputs a voltage signal proportional to the intensity of the backscattered light. It is important to note that the size of the casein micelles is small (on average, $120 \mathrm{~nm}$ ) compared with the optical fiber $(0.8 \mathrm{~mm})$, which allows the light beam to pass through many micelles.

Determining whey protein denaturation required the development of an optical technique for detecting the association of whey proteins occurring during thermal processing by the change in light backscatter of wavelength bands. As illustrated in Figure 2, an optical probe was sealed in a small volume sample cell and

(A)

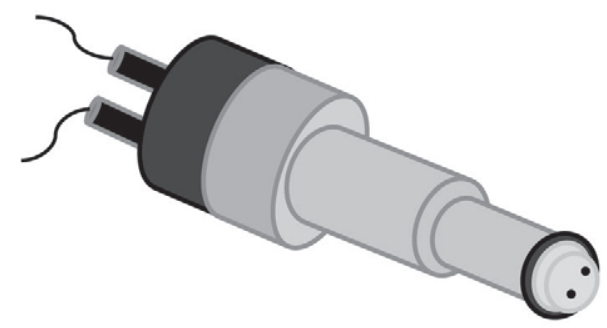

(B)

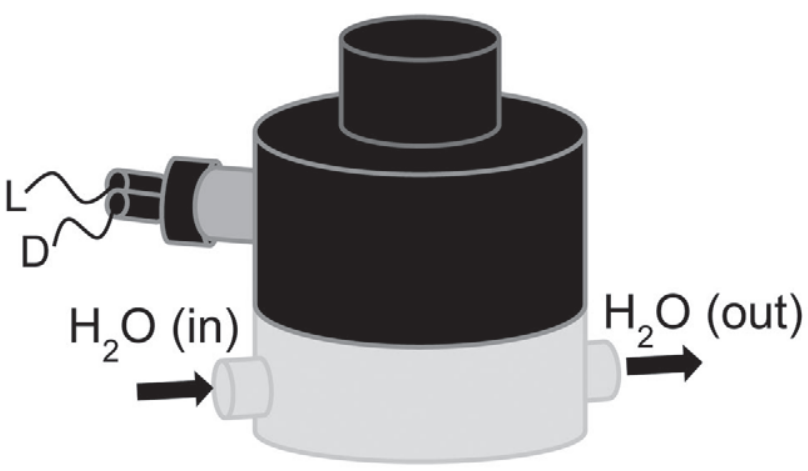

Figure 2. (A) Optical probe and (B) optical sample cell with probe: $\mathrm{L}=$ light source; $\mathrm{D}=$ detector. configured such that it could measure light backscatter using a fiber optic spectrometer (HR4000; Ocean Optics Inc., Dunedin, FL). Measurements were collected over a wavelength range of 300 to 1,100 nm using light from a tungsten halogen lamp (LS-1; Ocean Optics Inc.). Fiber optic cables, $0.8 \mathrm{~mm}$ in diameter, were used to connect the probe to the light source and spectrometer (Figure 3). The data acquisition system consisted of a personal computer $(\mathrm{PC})$, the spectrometer connected by a universal serial bus (USB) port, and data acquisition software (Spectra Suite; Ocean Optics Inc.). The backscatter response for a $25-\mathrm{nm}$ waveband was averaged over the 200- to 1,100-nm-wavelength range in the backscatter profile. All waveband ratios were analyzed by an SAS program (SAS Institute Inc., Cary, NC) using maximum R-square and PROC NLIN to determine the 10 ratios having the strongest first-order correlation with the whey protein denaturation extent measured by different physicochemical methods. Of those 10 waveband ratios, 2 were chosen for further analysis.

\section{Physicochemical Methods}

Several physicochemical methods were used to validate the optical response change in milk samples. Sodium dodecyl sulfate PAGE separated proteins based on their molecular weight and chemical structure. The addition of 2-mercaptoethanol indicated protein aggregation formed from disulfide bond formation. Disulfide bond content, formed by exposed sulfhydryl (-SH) groups, and protein aggregation served as indicators of protein denaturation. Differential scanning calorimetry (DSC) allowed the quantification of the amount of denaturation of the whey protein, $\beta-\mathrm{LG}$, by changes in enthalpy due to structure differences from heat treatment. By separating out the casein particles from the milk samples, determination of undenatured whey protein nitrogen (WPN) was measured by light transmission from a UV-visible spectrophotometer (Cary 300; Varian Inc., Palo Alto, CA). These values were correlated to a standard curve generated from Kjeldahl nitrogen values (standard procedure 15.134; Wehr and Frank, 2004).

SDS-PAGE Procedure. The SDS-PAGE procedure required the use of a Bio-Rad Mini-Protean 3 Cell loading apparatus (Bio-Rad Laboratories Inc., Hercules, CA). The samples had a protein concentration of 2.54 $\mathrm{mg} / \mathrm{mL}$. Preparation of the samples for electrophoresis required a 1:1 dilution with the sample buffer to obtain the appropriate composition of protein and SDS for running. A reducing agent ( $\beta$-mercaptoethanol) was added to some of the samples to breakdown the disulfide bonds occurring as a result of thermal treatment. Comparison between bands with a reducing agent and 


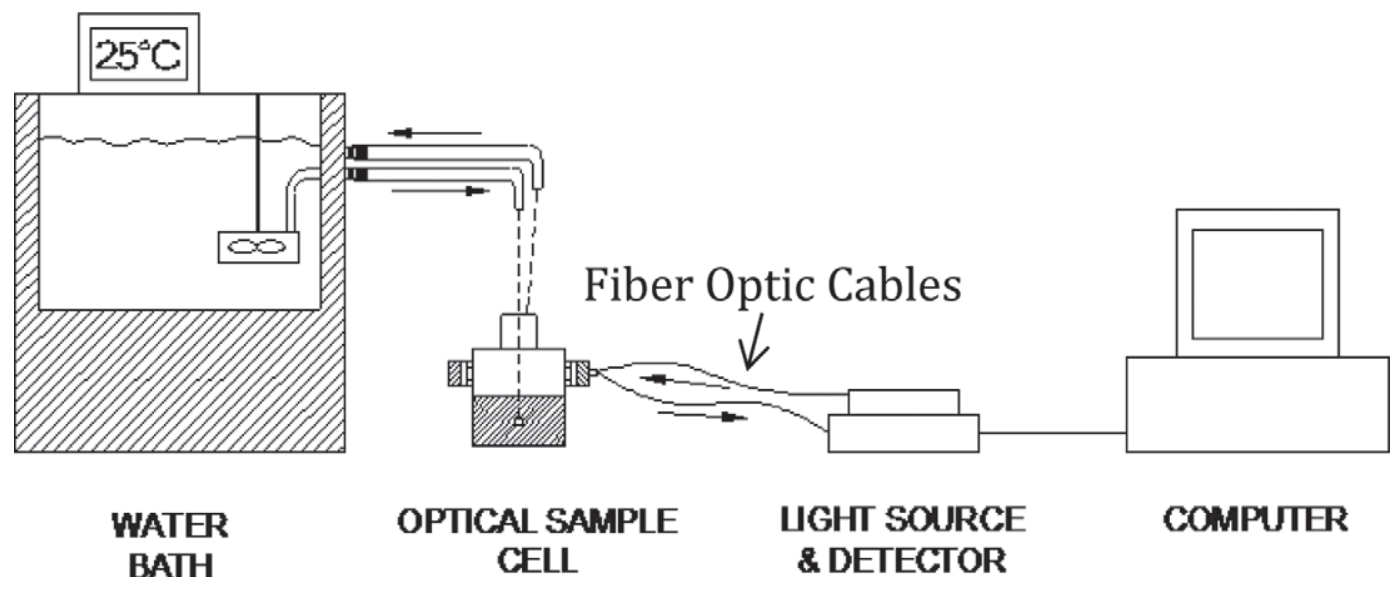

Figure 3. The optical system used to measure light backscatter.

without allowed for determination of protein aggregation. The resolving gel consisted of several ingredients, including acrylamide (15\%), Tris, SDS, glycerol, and ammonium persulfate, all of which were mixed together with tetramethylethylenediamine to cause polymerization.

Once the electrophoresis was performed, the stained gels were scanned using an LKB Ultrascan XL laser densitometer (Pharmacia, Far Hills, NJ). The densitometer quantified the bands based on their intensity and thickness. These values indicated the change in protein structure induced by the heat treatment. The scan outputs band thickness, intensity, and relative lane area for each lane on the gel. The thickness $(\mathrm{mm})$ and intensity (absorbance units, A.U.) for each lane were multiplied to calculate the lane area.

DSC Procedure. The DSC instrument was used to measure the enthalpy required to breakdown the disulfide bonds in the milk tested. The DSC procedure required hermetic pans and lids for the samples and a conventional differential scanning calorimeter (model 2920 MDSC V2.6A; TA Instruments, New Castle, DE) for calorimetry analysis. The enthalpy changes between treatments were used to quantify $\beta$-LG denaturation. The necessary protein concentration for conventional DSC must exceed 10\%. As liquid milk does not have the necessary protein concentration, the samples were freeze dried and reconstituted into a paste with a $0.067 M$ phosphate buffer ( $\mathrm{pH} 6.8$ ) for 20 to $25 \%$ protein concentration. The concentration of protein was measured using the Biuret method (Gornall et al., 1949) before reconstitution. The milk paste was reconstituted overnight to ensure full hydration. The DSC instrument required small amounts of the milk paste, ideally between 14 and $17 \mathrm{mg}$, in specific sealed aluminum pans. Air was used as a reference standard. The differential scanning calorimeter measured the dif- ference in the amount of heat required to increase the temperature of a sample material opposed to air. The instrument collected heat transfer rate [the quantity of heat energy transferred per unit of time $(\mathrm{d} Q / \mathrm{d} t)]$ versus temperature $(T)$ scan $(\mathrm{d} T / \mathrm{d} t)$ and time displayed in a graph. Enthalpy values were calculated by integrating the peak of output. Once the method was completed, the TS content of each sample was measured to adjust for solids content differences in milk sampling. Because the milk samples were low volume, slight differences in solids content would drastically influence enthalpy.

Undenatured WPN Procedure. Undenatured WPN measurement is a spectrophotometric method commonly used to determine the amount of native whey protein present in dairy products. A UV-visible spectrophotometer (Cary 300; Varian Inc.) was used to measure whey sample absorbances at $420 \mathrm{~nm}$. The following variation of an undenatured WPN determination method was used in this study. The milk at $37^{\circ} \mathrm{C}$ was saturated with $\mathrm{NaCl}$ and shaken periodically for 30 min, which caused aggregated proteins along with the casein micelles to separate from the whey. Then, the saturated milk passed through a filter, retaining the aggregated proteins and the casein micelles. Small drops of $\mathrm{HCl}$ were added to the filtered whey samples to produce turbidity in those samples with native protein remaining. Whey samples with high denaturation yielded low absorbance readings from a spectrophotometer. Absorbance readings at $420 \mathrm{~nm}$ that correlated with Kjeldahl nitrogen $(\mathrm{mg} / \mathrm{kg})$ revealed the amount of undenatured whey protein present in milk samples.

\section{Statistical Analysis}

The goal of the statistical regression analysis was the determination of a relationship between the optical data and the physicochemical data that would, thus, 
allow the prediction of denaturation using an optical response. The optical response was expected to be first order because thermal denaturation follows first-order kinetics. Thus, the analysis was directed toward finding a first-order relationship with time of heat treatment in the optical data. In addition, a simple ratio of 2 wave band responses was selected for analysis. A signal ratio provides an internal reference point for the signal and, thus, allows thermal denaturation changes to be more clearly detected.

All data obtained from each of the physicochemical procedures were processed and analyzed using SAS (SAS Institute Inc.; 2007). A ratio-generating program evaluated all possible ratio combinations from the optical data and listed the 10 signal ratios with the lowest $P$-value for a first-order trend. The ratio data chosen best for whey denaturation were analyzed by ANOVA, as were the physicochemical data. The physicochemical data were also regressed using PROC NLIN in SAS. The same first-order model (Equation 1) was used to describe all methods:

$$
y=B_{1}+B_{2} \cdot \mathrm{e}^{(-k t)},
$$

where $y=$ dependent variable, $B_{1}$ and $B_{2}$ are parameters, $k=$ reaction rate, and $t=$ time. The PROC CORR was applied to each of the physicochemical data versus the optical data. The Pearson correlation coefficients were generated to indicate the degree of linear dependence between the methods.

\section{RESULTS AND DISCUSSION}

\section{Physicochemical Analysis}

In the electrophoretic gels, the native $\beta-\mathrm{LG}$ band diminished from 0 to 25 min under nonreducing conditions for all 3 replications (Figure 4). The $\alpha$-LA band also decreased in a first- order response, although not as much as $\beta$-LG under nonreducing conditions (Table 1). This was in accordance to the fact that $\alpha$-LA has more heat tolerance than $\beta$-LG (Singh, 2007). The decrease in native whey protein bands was coupled with the presence of high-molecular protein bands. Both prominent whey protein bands remained constant under reducing conditions, despite an increase in treatment time, for all 3 replications. Also, under reducing conditions, the high molecular bands disappeared. The reducing agent added broke down formed disulfide bonds. For $\beta$-LG, the sole - $\mathrm{SH}$ group is normally occluded in the dimer structure and is only accessible after the structure has gone through significant changes, such as denaturation. This confirmed that the native protein structure was lost because of heat denaturation and caused disulfide bonding within and between the whey proteins, as well as $\beta$-LG with $\kappa$-CN. As much as $77 \%$ of $\beta$-LG and $57 \%$ of $\alpha$-LA native structure band area was lost from heat treatment. Recent literature (Anema et al., 2006) reported an $80 \%$ reduction in $\beta$-LG from heat treatment at $80^{\circ} \mathrm{C}$ for 20 min by SDS-PAGE analysis, which corresponds to the values found in the current study. Both whey proteins had a significant $(P<0.05)$ firstorder response to heat treatment time. The first-order response of $\beta-\mathrm{LG}$ to heat treatment is shown in Figure 5.

As the whey protein became more denatured from increasing heat treatment, the DSC curve unstable region shifted slightly to the right (i.e., higher temperature) and decreased in area (i.e., smaller enthalpy), as can be observed in Figure 6. In addition, the average values of the parameter maximum endothermic point $\left(\boldsymbol{T}_{\max }\right)$ shifted to higher temperatures (Table 2) as more denatured protein existed in a sample. The peak was integrated to determine the enthalpy change of whey proteins (particularly $\beta-\mathrm{LG}$ ). The enthalpy decreased with temperature treatment because less energy was absorbed to breakdown bonds due to previous heat degradation. The enthalpy was corrected by both the TS content and baseline enthalpy value. Total solids corrections account for any inconstancies from freeze drying or reconstitution. The baseline enthalpy value was the enthalpy change from a milk sample treated for total denaturation $\left(90^{\circ} \mathrm{C}\right.$ for $\left.1 \mathrm{~h}\right)$. The resulting enthalpy values corrected for TS are shown in Table 3.

The DSC heating scan in the unstable region is represented by 2 separate stages: the partial unfolding of the native protein structure (denaturation) and the intermolecular aggregation. Denaturation was endothermic because it involved the dissociation of intramolecular bonds (for whey proteins, noncovalent). The aggregation, which occurred immediately after the denaturation, was exothermic because of the formation of new bonds. This transition created the dip in the curve; the broadness of this area was a result of the denaturing of both $\beta$-LG and $\alpha$-LA. The enthalpy change decreased in a significant $(P<0.05)$ first-order trend, as shown in Figure 7.

The $T_{\max }$ for each of the milk samples listed in Table 2 did not behave entirely as expected. First of all, the $T_{\max }$ temperatures in this study were lower than the

Table 1. Nonlinear regression, $y=B_{1}+B_{2} \cdot \mathrm{e}^{(-k t)}$ (where $y=$ dependent variable, $B_{1}$ and $B_{2}$ are parameters, $k=$ reaction rate, and $t=$ time) for $\beta$-LG and $\alpha$-LA from SDS-PAGE

\begin{tabular}{lccccc}
\hline Model & $B_{1}$ & $B_{2}$ & $k\left(\mathrm{~min}^{-1}\right)$ & $\mathrm{R}^{2}$ & $P$-value \\
\hline$\beta$-LG & 0.158 & 0.735 & 0.094 & 0.79 & $<0.0001$ \\
$\alpha$-LA & 0.116 & 0.770 & 0.024 & 0.37 & 0.037 \\
\hline
\end{tabular}


$75^{\circ} \mathrm{C}$ found in Fitzsimons et al. (2007). The differences could have resulted from the high heat transfer rate that occurs as a result of the smaller sample size. Furthermore, conventional DSC reduces in accuracy for low protein concentration samples. For the $T_{\max }$ values in this study, they underwent an overall increase as thermal treatment increased over time for most of the replications. In between some time steps, the $T_{\max }$ value increased and then decreased slightly. This unusual trend may have been a result from errors in determining the baseline curve for integration. Or perhaps, the trend may have resulted from the aggregation that occurred during treatment before the DSC heating scan. The aggregates may have also absorbed energy to break down intermolecular bonds, which could cause an error in the peak areas and $T_{\max }$.

The undenatured WPN measurements had the most repeatability between the 2 replications compared

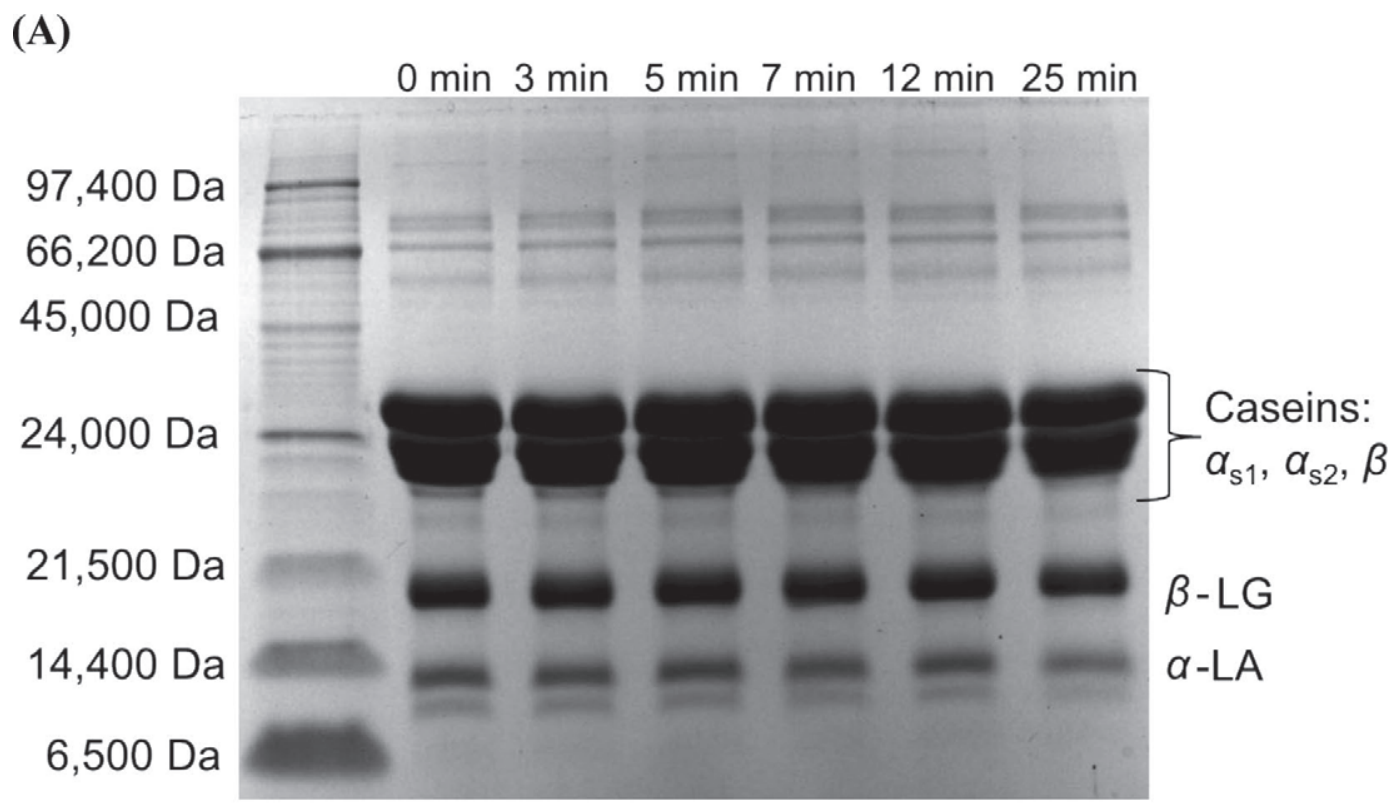

(B)

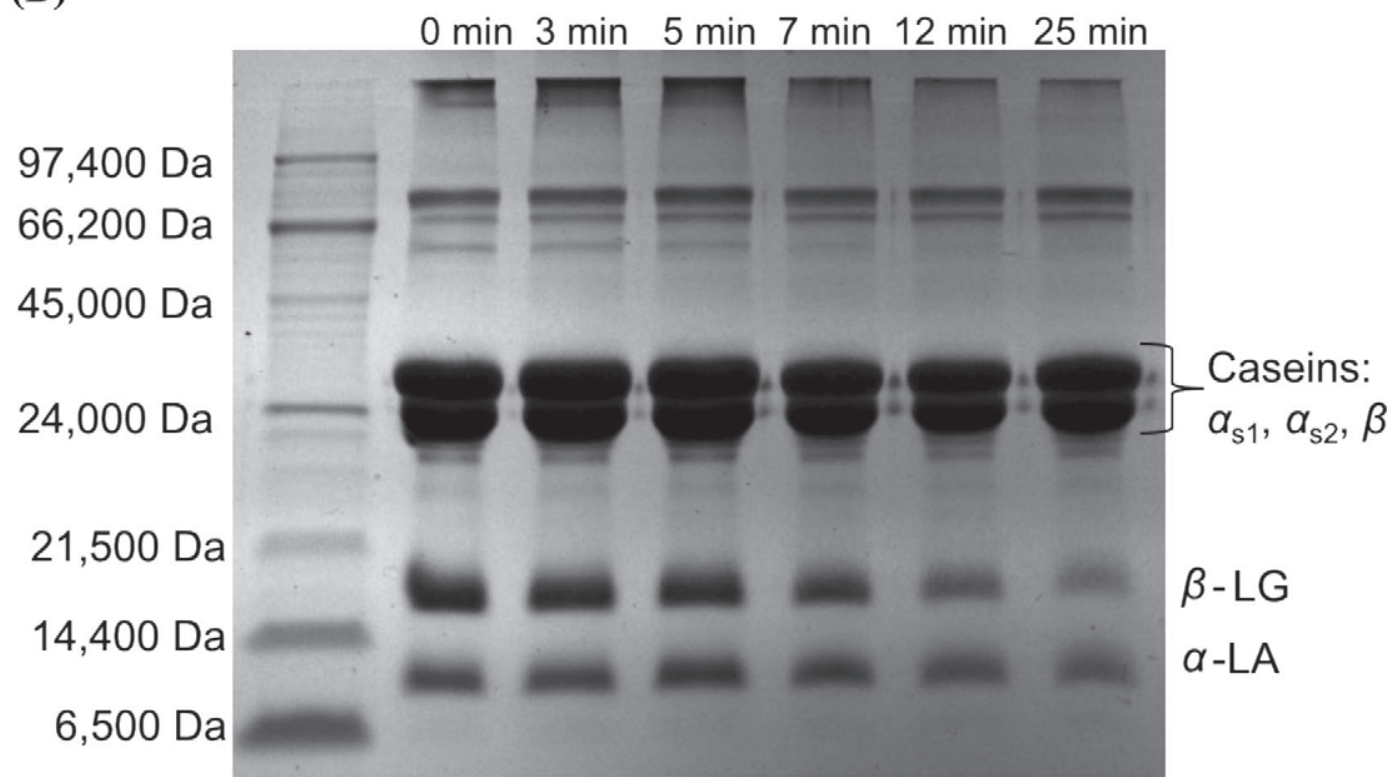

Figure 4. Sodium dodecyl sulfate PAGE gels. Heat treatment intensity increases to the right. (A) Reducing; (B) nonreducing. 


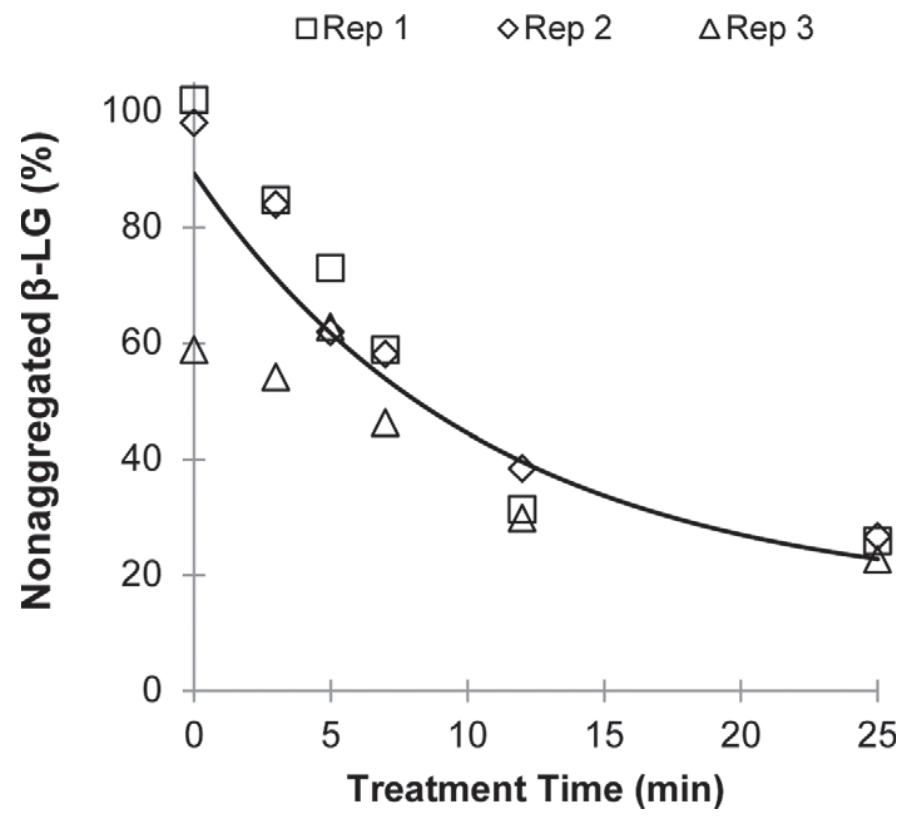

Figure 5. First-order response of $\beta$-LG to heat treatment from SDS-PAGE analysis. Rep = replication.

with the replications of the previous physicochemical methods. When measuring the amount of undenatured WPN by absorbance at $420 \mathrm{~nm}$, the decrease in turbidity of whey samples from increasing thermal exposure was visible. For the most severe treatment 25 (min at $80^{\circ} \mathrm{C}$ ), the sample solution appeared almost transparent. The filtered whey samples decreased in protein

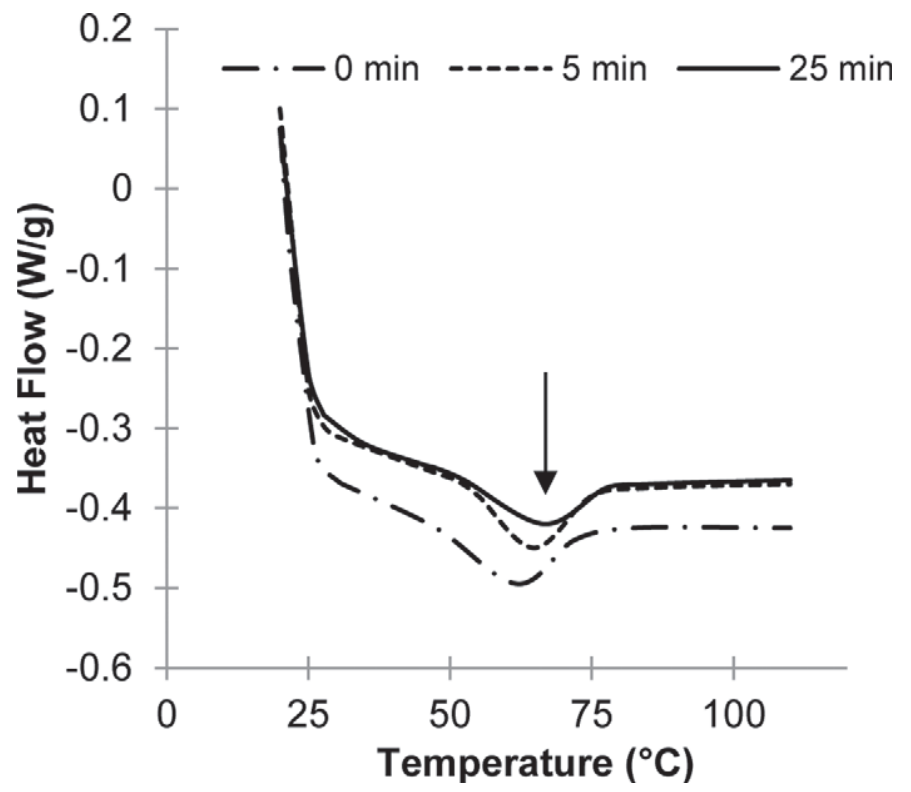

Figure 6. Differential scanning calorimetry (DSC) heating scan $\left(10.0^{\circ} \mathrm{C} / \mathrm{min}\right)$ for milk samples heated at $80^{\circ} \mathrm{C}$. Arrow indicates maximum endothermic point $\left(T_{\max }\right)$ for $25 \mathrm{~min}$.
Table 2. Maximum endothermic point $\left(T_{\max } ;{ }^{\circ} \mathrm{C}\right)$ values and average (Avg) for 6 treatment times at $80^{\circ} \mathrm{C}$ for 4 replications (Rep)

\begin{tabular}{llcccc}
\hline $\begin{array}{l}\text { Time } \\
(\min )\end{array}$ & Rep 1 & Rep 2 & Rep 3 & Rep 4 & Avg $T_{\max }$ \\
\hline 0 & 70.03 & 60.73 & 61.84 & 61.89 & 63.62 \\
3 & 64.11 & 61.68 & 63.93 & 61.85 & 62.89 \\
5 & 64.6 & 63.54 & 64.84 & 65.04 & 64.51 \\
7 & 66.71 & 61.83 & 63.6 & 61.81 & 63.49 \\
12 & 66.47 & 60.84 & 61.74 & 68.33 & 64.35 \\
25 & 63.15 & 65.42 & 62.4 & 66.6 & 64.39 \\
\hline
\end{tabular}

content with increasing thermal time because protein aggregates were retained. As expected, this reduction in absorbance also showed a first-order trend (Figure $8)$.

\section{Optical Analysis and Assessment of All Models}

The model for light backscatter showed a significant first-order increase $(P<0.05)$ in light backscatter with thermal treatment time. The wavebands within the range of 500 to $900 \mathrm{~nm}$ had the greatest response. Wavebands $<500 \mathrm{~nm}$ had small or negligible increases in light backscatter from treatment. Four wavebands (382, 632, 682, and $832 \mathrm{~nm})$ were chosen for further analysis based on their statistical significance firstorder correlation with the physicochemical data (determined from ratio analysis described above). The 4 wavebands make up 2 ratios, one with close wavebands $\left(\mathrm{R}_{682 \_632}\right)$ and one with far apart wavebands $\left(\mathrm{R}_{832 \_382}\right)$. The optical results show a strong first-order response to heat treatment with 2 outliers (Figures 9 and 10).

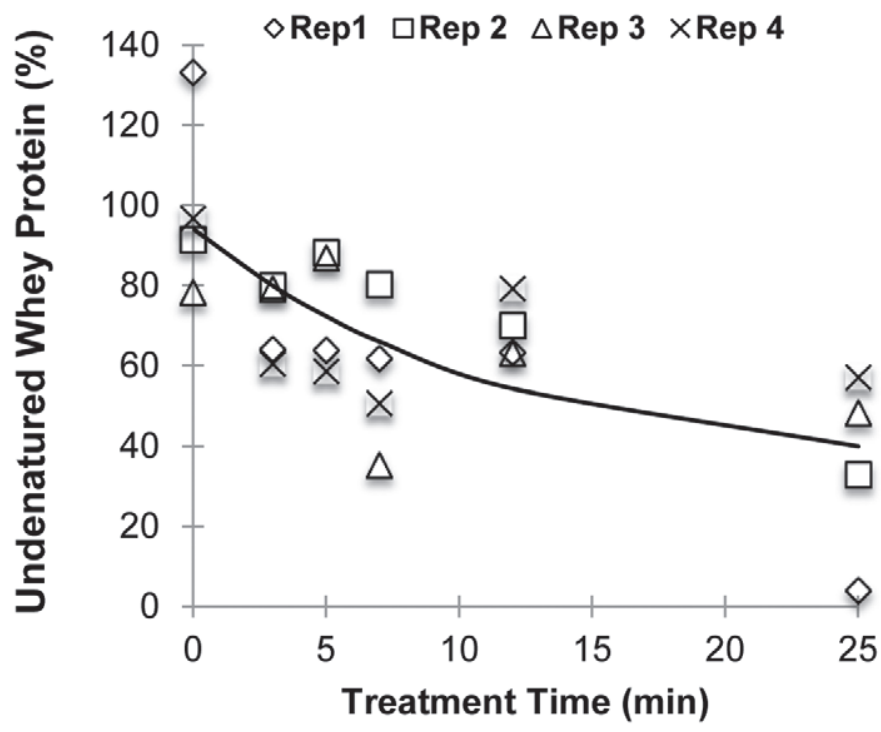

Figure 7. First-order response of undenatured whey proteins from differential scanning calorimetry (DSC) analysis. Rep = replication. 


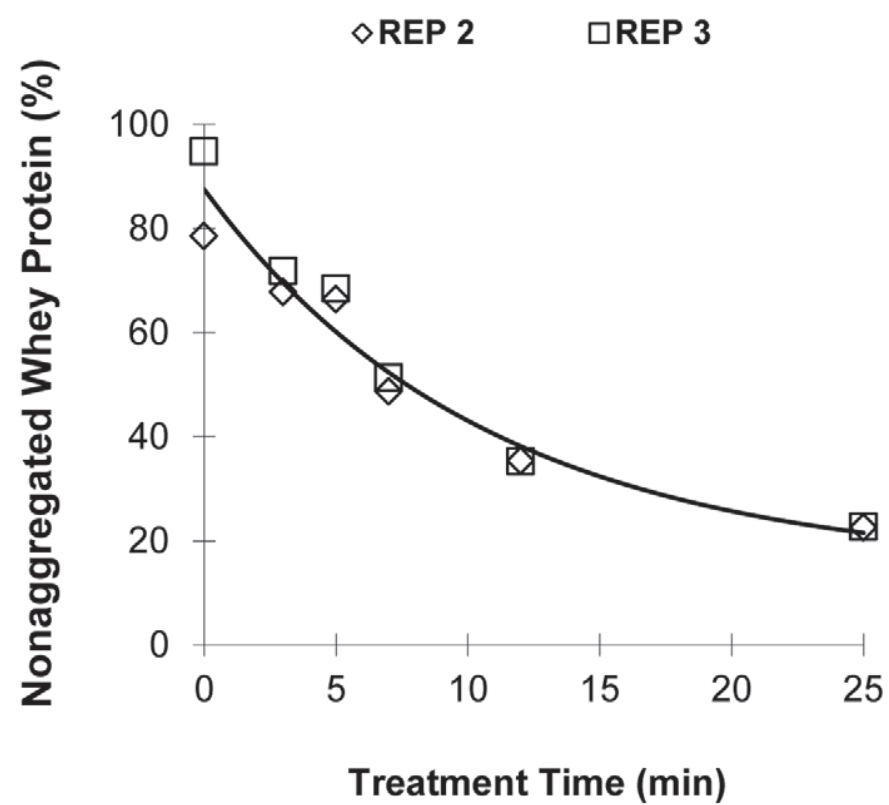

Figure 8. First-order response of nonaggregated whey protein from undenatured whey protein nitrogen $(\mathrm{WPN})$ analysis. $\mathrm{REP}=$ replication.

The outliers exist at $5 \mathrm{~min}$ for replication 4 and at 25 min for replication 3 . As these 2 samples were outliers for almost all ratios, it was assumed that an experimental error occurred during heat treatment and these points were ignored when evaluating the ratio models. Displayed in Table 4 are the models for a first-order

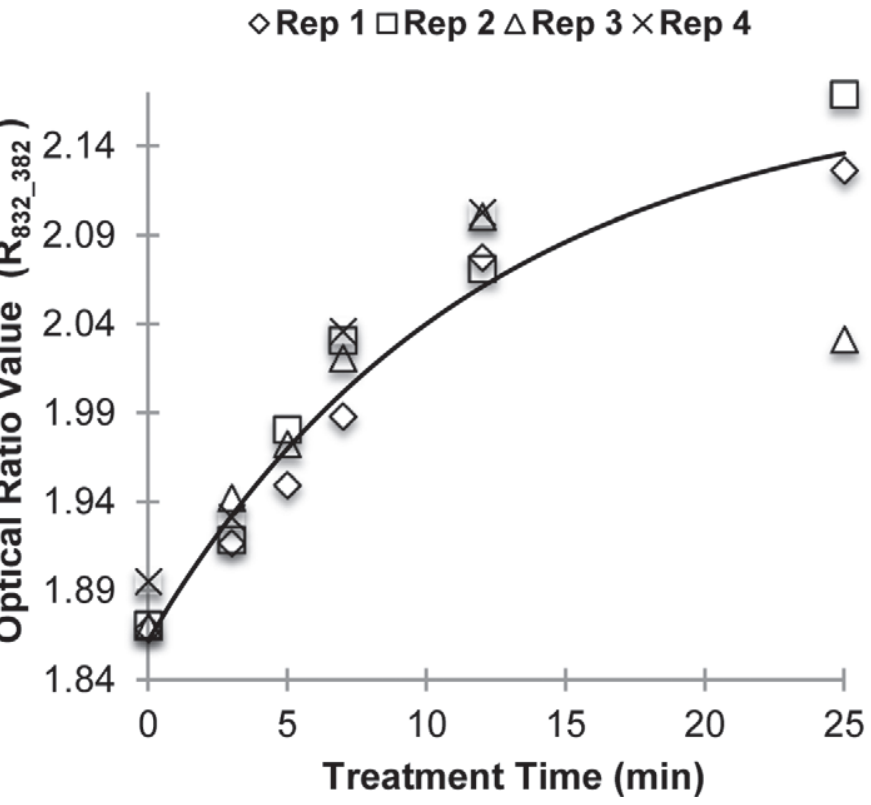

Figure 9. First-order response of optical ratios at wavebands of 832 and $382 \mathrm{~nm}\left(\mathrm{R}_{832 \_382}\right)$ from optical analysis. Rep = replication.

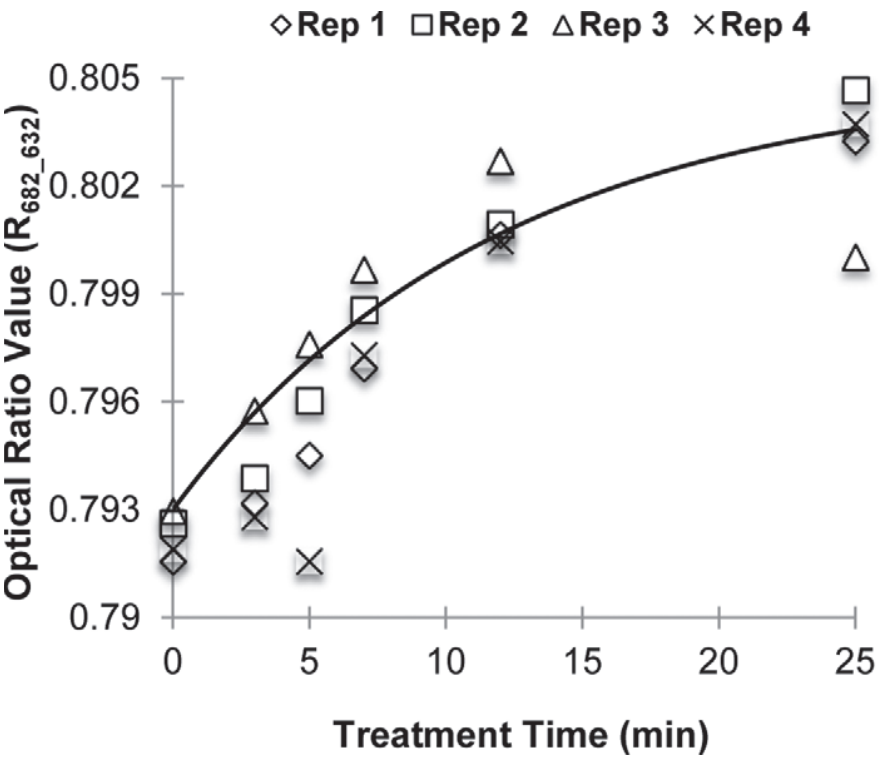

Figure 10. First-order response of optical ratios at wavebands of 682 and $632 \mathrm{~nm}\left(\mathrm{R}_{682 \_632}\right)$ from optical analysis. $\mathrm{Rep}=$ replication.

regression for the 3 physicochemical methods and 2 optical ratios. All models were significant $(P<0.05)$. The reaction rate $(k)$ remained equivalent for all models at $0.089 \pm 0.005 \mathrm{~min}^{-1}$. Also, the ratio $\mathrm{R}_{832 \_382}$ showed the greatest percentage difference between control and heat treatment, which suggests that it is a strong indicator of whey denaturation. As each of the method models corresponded to the denaturation of whey proteins, it is expected that reaction rates were similar. All physicochemical methods significantly correlated with both optical ratios.

The correlations of each physicochemical method indicated that with increasing temperature, fewer undenatured proteins remained, more denatured proteins existed, and this significantly $(P<0.05)$ correlated to larger light backscatter ratios in the milk sample. For undenatured WPN and DSC methods, the direct correlation was light backscatter to total undenatured whey protein present; however, $\beta-\mathrm{LG}$ is the dominant whey protein. The SDS-PAGE analysis separated the

Table 3. Enthalpy values $(\mathrm{J} / \mathrm{g})$, corrected for TS $[6$ treatment times at $80^{\circ} \mathrm{C}$ for 4 replications (Rep)]

\begin{tabular}{lcccc}
\hline $\begin{array}{l}\text { Time } \\
(\text { min })\end{array}$ & Rep 1 & Rep 2 & Rep 3 & Rep 4 \\
\hline 0 & 9.72 & 6.68 & 5.72 & 7.06 \\
3 & 4.68 & 5.83 & 5.78 & 4.42 \\
5 & 4.66 & 6.44 & 6.34 & 4.28 \\
7 & 4.51 & 5.86 & 2.57 & 3.70 \\
12 & 4.62 & 5.12 & 4.60 & 5.79 \\
25 & 0.29 & 2.40 & 3.52 & 4.17 \\
\hline
\end{tabular}


Table 4. Parameters and significance of first-order model regression, $y=B_{1}+B_{2} \cdot \mathrm{e}^{(-k t)}$ (where $y=$ dependent variable, $B_{1}$ and $B_{2}$ are parameters, $k=$ reaction rate, and $t=$ time)

\begin{tabular}{lccccc}
\hline Parameter & $B_{1}$ & $B_{2}$ & $k\left(\mathrm{~min}^{-1}\right)$ & $\mathrm{R}^{2}$ & $P$-value \\
\hline I. Optical ratio $(832 \mathrm{~nm} / 382 \mathrm{~nm})$ & 2.173 & -0.311 & 0.085 & 0.78 & $<0.0001$ \\
II. Optical ratio $(682 \mathrm{~nm} / 632 \mathrm{~nm})$ & 0.805 & -0.013 & 0.085 & 0.84 & $<0.0001$ \\
III. SDS-PAGE & 0.158 & 0.735 & 0.094 & 0.79 & $<0.0001$ \\
IV. DSC & 0.333 & 0.699 & 0.089 & 0.50 & 0.0006 \\
V. Undenatured $\mathrm{WPN}^{2}$ & 0.146 & 0.739 & 0.094 & 0.95 & $<0.0001$ \\
\hline
\end{tabular}

${ }^{1}$ Differential scanning calorimetry.

${ }^{2} \mathrm{WPN}=$ whey protein nitrogen.

whey proteins based on molecular weight. Therefore, the light backscatter was directly correlated with $\beta$-LG nativity. Some of the correlations were stronger than others (shown in Table 5). From these correlation coefficients, the DSC appeared inferior to the other physicochemical and optical ratio methods. Although significant, the DSC model had a higher $P$-value for all correlations than the other models. Its correlation was the weakest with all models; the strongest correlation coefficient being 0.60 with $\mathrm{R}_{682} 632$. Overall, these correlations were strong, which indicates the strength of both optical ratio models. In other words, 3 vastly different physicochemical methods showed that both optical ratios were significantly correlated with whey protein denaturation.

All models appeared to represent protein denaturation, which is a known first-order reaction. All methods yielded equivalent reaction rates (Table 4). The reaction rates for $\beta$-LG found in this study (on average, $0.089 \mathrm{~min}^{-1}$ ) was consistent with those in the recent literature. In Sava et al. (2005), the surface -SH groups denatured at a rate of $0.0899 \pm 0.0075 \mathrm{~min}^{-1}$ from thermal exposure at $78^{\circ} \mathrm{C}$. The surface - $\mathrm{SH}$ groups participate in dimer formation of $\beta-\mathrm{LG}$ and aggregation with $\kappa-\mathrm{CN}$ and other proteins. Even though significantly equivalent to all models, the optical ratio models slightly underestimated the rate of denaturation (Table 4). This may be because of the model compounding effects of the protein denaturing and aggregating, as the aggregation caused by denaturation increases the diameter of the proteins, which increases light scatter.

Table 5. The correlation matrix between physicochemical methods and optical ratios (R; Pearson correlation coefficients are listed)

\begin{tabular}{lccc}
\hline $\begin{array}{l}\text { Optical } \\
\text { ratio }(n m)\end{array}$ & SDS-PAGE & DSC $^{1}$ & $\begin{array}{c}\text { Undenatured } \\
\text { WPN }^{2}\end{array}$ \\
\hline $\mathrm{R}_{832 \_382}$ & 0.80 & 0.55 & 0.84 \\
$\mathrm{R}_{682 \_632}$ & 0.78 & 0.60 & 0.90 \\
\hline
\end{tabular}

${ }^{1}$ Differential scanning calorimetry.

${ }^{2} \mathrm{WPN}=$ whey protein nitrogen.

\section{CONCLUSIONS}

Whey protein denaturation from heat treatment was confirmed by all physicochemical methods of analysis (SDS-PAGE, DSC, and undenatured WPN). Disulfide bond formation was confirmed after treatment and had a clear role in aggregation of denatured protein $\beta$-LG with itself or other milk proteins, or both. The whey protein denaturation followed a first-order response, as indicated by physicochemical methods of analysis (SDS-PAGE, DSC, and undenatured WPN). The SDSPAGE and undenatured WPN models showed greater consistency than the conventional DSC model for calculating whey protein denaturation. Light backscatter also increased proportionately to heat exposure with a first-order response. The reaction rate for $\beta-\mathrm{LG}$ denaturation was measured as $0.089 \pm 0.005 \mathrm{~min}^{-1}$ using the light backscatter, SDS-PAGE, WPN, and DSC methods. Correlation of the light backscatter waveband ratios to $\beta$-LG denaturation and other whey proteins were found, which suggests that light backscatter could potentially be used for inline measurement of $\beta-L G$ denaturation and (or) general whey protein denaturation.

\section{REFERENCES}

Allogio, V., F. Caponio, A. Pasqualone, and T. Gomes. 2000. Effects of heat treatment on the rennet clotting time of cow and goat milk. Food Chem. 70:51-55.

Alvarez, D., M. Castillo, F. A. Payne, and Y. L. Xiong. 2009. A novel fiber optic sensor to monitor beef emulsion stability using visible light scattering. Meat Sci. 81:456-466.

Anema, S. G., and Y. Li. 2003. Association of denatured whey proteins with casein micelles in heated reconstituted milk and its effect on casein micelle size. J. Dairy Res. 70:73-83.

Anema, S. G., S. K. Lee, and H. Klostermeyer. 2006. Effect of protein, nonprotein-soluble components, and lactose concentrations on the irreversible thermal denaturation of $\beta$ - lactoglobulin and -lactalbumin in skim milk. J. Agric. Food Chem. 54:7339-7348.

Brown, R. J. 1999. Fundamentals of Dairy Chemistry. Blackie Academic \& Professional, London, UK.

Castillo, M., F. A. Payne, C. L. Hicks, and M. C. Lopez. 2000. Predicting cutting and clotting time of coagulating goat's milk using diffuse reflectance: Effect of $\mathrm{pH}$, temperature, and enzyme concentration. Int. Dairy J. 10:551-562.

Castillo, M., F. A. Payne, M. B. López, E. Ferrandini, and J. Laencina. 2005. Optical sensor technology for measuring whey fat concentration in cheese making. J. Food Eng. 71:354-360. 
Fagan, C. C., M. Castillo, C. P. O'Donnell, D. J. O'Callaghan, and F. A. Payne. 2007a. Optical measurement of curd shrinkage during cheese manufacturing. J. Dairy Sci. 90(Suppl. 1):145. (Abstr.)

Fagan, C. C., C. P. O'Donnell, D. J. O'Callaghan, G. Downey, E. M. Sheehan, C. M. Delahunty, C. Everard, T. P. Guinee, and V. Howard. 2007b. Application of mid-infrared spectroscopy to the prediction of maturity and sensory texture attributes of cheddar cheese. J. Food Sci. 72:130-137.

Fitzsimons, S. M., D. M. Mulvihill, and E. R. Morris. 2007. Denaturation and aggregation processes in thermal gelation of whey proteins resolved by differential scanning calorimetry. Food Hydrocoll. 21:638-644.

Gornall, A., C. Bardawill, and M. David. 1949. Determination of serum proteins by means of the biuret reaction. J. Biol. Chem. 177:751-766.

Guyomarc'h, F., C. Queguiner, A. J. R. Law, D. S. Horne, and D. G. Dalgleish. 2003. Role of the soluble and micelle-bound heatinduced protein aggregates on network formation in acid skim milk gels. J. Agric. Food Chem. 51:7743-7750.

Hardy, J. 1989. El desuerado del coagulo. Pages 35-55 in El Queso. A. Eck, ed. Omega S. A., Barcelona, Spain.

IDFA (International Dairy Foods Association). 2010. Dairy Facts: 2010 Edition. IDFA, Washington, DC.

Payne, F. A., C. L. Hicks, and P.-S. Shen. 1993. Predicting the optimal cutting time of coagulating milk using diffuse reflectance. J. Dairy Sci. $76: 48-61$.
Sava, N., I. Van der Plancken, W. Claeys, and M. Hendickx. 2005. The kinetics of heat-induced structural changes of $\beta$-lactoglobulin. J. Dairy Sci. 88:1646-1653.

Schorsch, C., D. K. Wilkins, M. G. Jones, and I. T. Norton. 2001. Gelation of casein-whey mixtures: Effects of heating whey proteins alone or in the presence of casein micelles. J. Dairy Res. 68:471-481.

Siegel, H., and J. Howell. 2002. Scattering of energy by particles and fibers. Pages 470-490. Thermal Radiation Heat Transfer. Taylor \& Francis, New York, NY.

Singh, H. 2007. Interactions of milk proteins during the manufacture of milk powders. Lait 87:413-423.

USDEC (United States Dairy Export Council). 2012. A Year in Review. USDEC, Arlington, VA.

Walstra, P., T. J. Geurts, A. Noomen, A. Jellema, and M. A. J. S. van Boekel. 2001. Ciencia de La Leche y Tecnología de Los Productos Lácteos. Acribia, Zaragoza, Spain.

Waungana, A., H. Singh, and R. J. Bennett. 1997. Influence of denaturation and aggregation of $\beta$ - lactoglobulin on rennet coagulation properties of skim milk and ultrafiltered milk. Food Res. Int. 29:715-721.

Wehr, H. M., and J. F. Frank. 2004. Standard Methods for the Examination of Dairy Products. American Public Health Association, Washington, DC. 